\title{
Evaluation of PCNA, Caspase 3 and E-cadherin on the Ventral Prostate of Soy Treated Rats
}

\author{
B. Oltra ${ }^{1}$, J.M. Pozuelo ${ }^{1}$, R. Rodríguez ${ }^{1}$, I. Ingelmo ${ }^{2}$, R. Arriazu ${ }^{1}$ and L. Santamaría, \\ ${ }^{I}$ Department of Basic Medical Sciences, School of Medicine, CEU San Pablo University, 28668-Madrid, Spain \\ ${ }^{2}$ Department of Anesthesia and Reanimation, Ramón y Cajal Hospital, 28034-Madrid, Spain \\ ${ }^{3}$ Department of Anatomy, Histology, and Neuroscience, School of Medicine, Autonomous University of Madrid, 28029- \\ Madrid, Spain
}

\begin{abstract}
The incidence of certain cancers, including prostate cancer, is considerably higher in western countries than in Southeast Asia. Many studies have linked soy consumption to the lower incidence of prostate cancer in these countries. Twenty male Sprague-Dawley rats were randomized and divided into a control group and a group treated with soy. The ventral prostates of each animal were sectioned and stained with hematoxilin-eosin for morphological description and immunostained to detect PCNA, cleaved caspase 3 and E-cadherin immunoreactivities. Estimates of the number of total epithelial cells and the number of epithelial cells immunoreactive to PCNA and cleaved caspase 3 were calculated using the optical disector technique. Measurement of E-cadherin was carried out by calculating the volume fraction of epithelium immunostained by E-cadherin. Soy treated group showed atrophy in the epithelium and a diminished expression of PCNA, cleaved caspase 3 and E-cadherin, which means there is a reduced cell proliferation, apoptosis through caspases way and cell adherence. It can be concluded that soy treatment induces atrophy in the epithelium by reducing cell proliferation.
\end{abstract}

Keywords: Apoptosis, cell adherence, cell proliferation, rat prostate, soy, stereology.

\section{INTRODUCTION}

The incidence of certain cancers, including prostate cancer, is considerably higher in western countries than in Southeast Asia. There are several epidemiological studies that attribute this lower incidence to environmental factors, because the incidence in Asians that move to western countries is similar to that of the population of said countries [1, 2]. Many studies have linked soy consumption to the lower incidence of prostate cancer in Asian countries [3-8].

These beneficial properties of the soy are associated to organic compounds called isoflavones [9], which appear in significant amounts in soybeans. Isoflavones are diphenolic compounds with a chemical structure similar to estrogens, although they are not steroidal. This is why they are commonly known as phytoestrogens.

Isoflavones protect against cancer by mechanisms not yet well known, but many studies suggest that it is due to their activity as estrogen receptor modulators $[4,5,10,11]$. Other studies have linked soy consumption with low insulindependent growth factor (IGF), which has also been associated with the development of prostate cancer [12]. Other

*Address correspondence to this author at the Departamento de Anatomía, Histología y Neurociencia, Facultad de Medicina. Universidad Autónoma de Madrid, Arzobispo Morcillo, 1. 28029, Madrid, Spain; Tel: 914975 367; Fax: 914975 333; E-mail: luis.santamaria@uam.es proposed mechanisms are inhibition of angiogenesis $[4,13]$, inhibition of cell proliferation, induction of apoptosis [7] and their antioxidant activity [14-16].

Immunohistochemical techniques and quantitative stereological methods were used to study those different mechanisms. The proliferating cell nuclear antigen (PCNA) has been used in numerous studies as a marker of cell proliferative status, associating an increased proliferation to an abnormal cell growth in tumor tissues [17-19].

Caspases are fundamental components of the mammalian apoptotic machinery. Caspase 3 is a prototypical enzyme that becomes activated during apoptosis in a wide variety of tissues [20]. On the other hand, there is evidence of loss of cleaved caspase 3 protein expression in prostate cancer [21]. The quantification of immunoexpression of cleaved caspase 3 may constitute a good method for measuring apoptotic activity in prostate cancer and its precursors.

E-cadherin is a molecule involved in adhesion between epithelial cells and therefore it has been linked to invasiveness of many malignant tumors [22]. It is thought that the gene that codify for E-cadherin is a suppressor gene, because there have been mutations at these level linked to a lesser immunoexpression of E-cadherin at immunostainings [23].

The aim of this work is to study morphological and quantitative changes occurring in the ventral prostate of rats treated with soy as well as soy effects on cell proliferation, cell-adherence and apoptosis. 


\section{MATERIALS AND METHODOLOGY}

\section{Animals}

Twenty male Sprague-Dawley rats were randomized and divided into two groups, according to treatment, that began in all cases at three months old. Soy-enriched chow (Teklad Gobal 18\% Protein Rodent Diet, Harlan Interfauna, Ibérica SL. Barcelona, Spain) was used for feeding the first group. The second group was used as a control and was fed with Pan Lab Chow (Panlab, Barcelona, Spain). All animals were kept in a controlled environment with light/dark cycle $12 \mathrm{~h} / 12 \mathrm{~h}, 45-55 \%$ humidity, $20-22^{\circ} \mathrm{C}$ and fed "ad libitum". Animals fed with soy-enriched chow were estimated to have an average intake of $250 \mathrm{mg} / \mathrm{kg} /$ day of isoflavones.

During this work, all animal studies were conducted in accordance to local directives ruled by "Real Decreto 223/1988" and "Orden de 13 de Octubre".

Animals were sacrificed at eighteen months old by narcosis with carbon dioxide. Previous studies [24] showed that such aged animals will probably develop prostate damages and so we shall compare damages appearing in treated and non-treated animals.

All animals were weighed and the mean of each group was calculated. The means $\pm \mathrm{SD}$ were compared by a $\mathrm{t}$ student test, so that we could dismiss a weight loss in animals treated with soy. Immediately after that, prostates were removed from each animal and were also weighed. Total fresh volume of each prostate was determined by water displacement. Then, the ventral lobes were separated from the dorsolateral ones and the volume and weight of each lobe were also determined.

The ventral prostates were embedded in paraffin and the paraffin blocks were used to obtain $10 \mu \mathrm{m}$-thick serial sections. Sections from each animal were stained with hematoxylin-eosin for morphological description. The percentage of cases with at least one dysplastic lesion was also determined in each group of animals, taking into account both mild and severe dysplasia. Mild dysplasia is characterized by a higher number of nuclei appearing piled and with alterations in their shape, size and polarity. Severe dysplasia presents a thicker epithelium, which acquires cribriform structure, and also shows alterations in the shape and size of nuclei. In addition nucleoli and mitotic figures are frequently observed [24].

\section{Immunohistochemical Methods}

Slides from each animal of both groups were immunostained. Deparaffined and rehydrated tissue sections were treated for $30 \mathrm{~min}$ with hydrogen peroxide $0.3 \%$ to block endogenous peroxidase. To detect PCNA, caspase 3 and E-cadherin immunoreactivities, sections were incubated with anti-PCNA antibody (Biomeda. Foster City, CA, USA) diluted at 1:400; anti-caspase 3 antibody (Cell Signaling. Boston, USA) diluted at 1:30; and anti-E-cadherin antibody (Novocastra. Newcastle, UK) diluted at 1:150. All incubations with primary antisera were kept overnight at $4^{\circ} \mathrm{C}$. Pretreatment of sections by heat in citrate buffer $\mathrm{pH} 6.0$ using a pressure cooker was performed to enhance all the immunostainings $[25,26]$. The immunohistochemical method was performed by an indirect technique using the antibody detection kit Histostain SP (Kit Histostain SP, Zymed Laboratories. Carlsbad, USA). The immunostaining reaction product was developed using $0.1 \mathrm{~g}$ diaminobenzidine (DAB) $\left(3,3^{\prime}, 4,4^{\prime}\right.$-Tetraminobiphenyl, Sigma, St. Louis, USA) in PBS, pH $7.4(200 \mathrm{~mL})$, plus $40 \mu \mathrm{l}$ of hydrogen peroxide.

After immunoreactions, sections were counterstained with Harris hematoxylin. All slides were dehydrated in ethanol and mounted in a synthetic resin (Depex, Serva, Heidelberg, Germany).

\section{Quantitative Methods}

Estimates of the number of total epithelial cells and the number of epithelial cells immunoreactive to PCNA and cleaved caspase 3 were calculated using the optical disector technique, an unbiased stereological method [27, 28]. Measurements were carried out using an Olympus microscope fitted with a motorized stage and equipped with an X100 oil immersion lens (numerical aperture of 1.4) at a final magnification of X1200, employing the stereological software CAST-GRID [29].

In each selected field from PCNA-immunostained sections, the numerical density $\left(\mathrm{N}_{\mathrm{v}}\right)$ of epithelial cells was estimated. The $\mathrm{N}_{\mathrm{v}}$ of epithelial cells immunoreactive to PCNA was simultaneously estimated. In cleaved caspase 3 stained sections, positive epithelial cells were evaluated. In all cases, the unit used for counting was the nucleus eligible according to the Sterio rule [30].

The $\mathrm{N}_{\mathrm{v}}$ is determined by the formula: $\mathrm{N}_{\mathrm{v}}=\mathrm{Q}^{-} / \Sigma \mathrm{V}$ dis, where: $\mathrm{Q}^{-}=$number of eligible nuclei, $\Sigma \mathrm{V}$ dis $=$ Sum of the volumes of the measured disectors.

In this case, the measured disectors were those, whose upper-right corner hit the epithelium, since the reference volume is the epithelium. To determine the volume of the disectors, the area of each disector was multiplied by its height, which in this case is $5 \mu \mathrm{m}$. The absolute number of epithelial cells was then calculated multiplying $N_{v}$ by the volume of epithelium. These calculations are expressed in number of cells per $\mu^{3}$. For convenience, the results were expressed in number of cells $/ \mathrm{mm}^{3}$.

Labeling indices for PCNA and cleaved caspase 3 were calculated: Li PCNA $=\mathrm{Q}^{-}$PCNA / $\mathrm{Q}^{-}$, where: $\mathrm{Q}^{-}$PCNA = number of nuclei immunoreactive for PCNA, $\mathrm{Q}^{-}=$total number of nuclei; $\mathrm{Li}$ casp $=\mathrm{Q}^{-}$casp $/ \mathrm{Q}^{-}$, where: $\mathrm{Q}^{-}$casp $=$number of immunoreactive cells to cleaved caspase $3, \mathrm{Q}^{-}=$total number of nuclei.

The volume fraction of epithelial cytoplasm immunostained by E-cadherin will be estimated by previously calculating the volume fractions of epithelium and glandular lumen: $\mathrm{V}_{\mathrm{V}} \mathrm{Ep}=\operatorname{dis} \mathrm{Ep} /$ disTot, $\mathrm{V}_{\mathrm{V}} \mathrm{L}=$ disL / disTot, where: $\mathrm{V}_{\mathrm{V}} \mathrm{Ep}=$ epithelium volume fraction, $\mathrm{V}_{\mathrm{V}} \mathrm{L}=$ volume fraction of glandular lumen, disEp = number of disectors hitting the epithelium, disL $=$ number of disectors hitting the glandular lumen, disTot $=$ total number of disectors hitting the glands $($ disEp + disL). The volume fraction of epithelium immunostained by E-cadherin was calculated as follows: $V_{\mathrm{V}}$ cadE $=\sum \mathrm{P}$ cadE $+/ \sum \mathrm{P}$ Ep, where: $\sum \mathrm{P}$ cadE $+=$ number of points hitting epithelium immunoreactive to E-cadherin, $\sum \mathrm{P} \mathrm{Ep}=$ number of points hitting both, immunoreactive and non- 


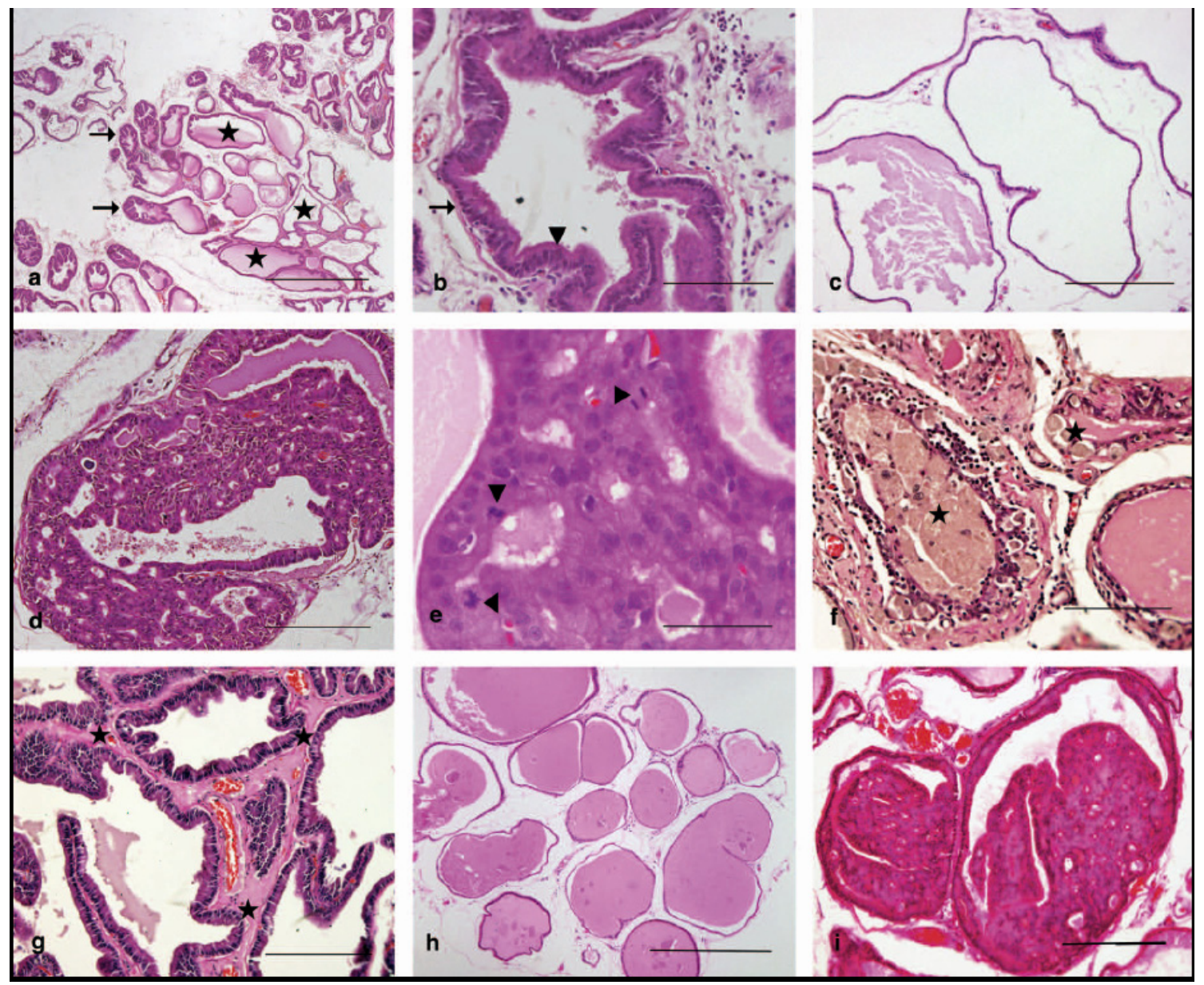

Fig. (1). Histology of the ventral prostate of rats in both groups (hematoxylin-eosin):

a- Peripheral acini with smaller size and a higher epithelium (arrows) and central acini more dilated with flattened epithelium (stars) in a control rat. The bar represents $1 \mathrm{~mm}$.

b- Cylindrical monoestratified epithelium with nuclei in basal position (arrow) in a control rat. In some areas the epithelium may look pseudostratified (arrowhead). The bar represents $100 \mu \mathrm{m}$.

c- Some acini have atrophic epithelium in control rats. The bar represents $200 \mu \mathrm{m}$.

d- Dysplastic lesion with cribriform structure in a control rat. The bar represents $200 \mu \mathrm{m}$.

e- Some mitotic figures in a dysplastic lesion from a control rat (arrowheads). The bar represents 50 $\mu \mathrm{m}$.

f- Prostatitis with invasion of macrophages (stars) in acini and interstitium in a control rat. The bar represents $100 \mu \mathrm{m}$.

g- Fibrosis in the interstitium (stars) of a control rat. The bar represents $200 \mu \mathrm{m}$.

h- Large areas of atrophy in the epithelium of a soy treated animal. The bar represents $500 \mu \mathrm{m}$.

i- Dysplastic lesion with cribriform structure in a soy treated rat. The bar represents $400 \mu \mathrm{m}$.

immunoreactive epithelium. To calculate absolute volumes, volume fractions were multiplied by the ventral prostate volume.

\section{Statistical Analysis}

The means and SD were calculated for all the parameters measured and a Student t-test was applied to compare these means between the two groups of animals at a level of significance $\mathrm{p}<0.05$.

\section{RESULTS}

\section{Qualitative Results}

Average weight of the control group was of $653 \pm 18 \mathrm{~g}$, whereas in the soy treated group it was of $644 \pm 18 \mathrm{~g}$. There were no significant differences between those means.
Prostates from the control group have peripheral acini with a smaller size than the central ones (Fig. 1a). The epithelium of these acini is cylindrical but sometimes may appear pseudostratified (Fig. 1b) and also have small papillae that protrude to the lumen. The central acini are dilated and show atrophic epithelium in some areas, characterized by a decrease in its height (Fig. 1c). The stroma is loose and well developed.

In this group, dysplasias are generally located in central acini. In all cases, the lesions appear well developed showing a cribriform structure (Fig. 1d, e). Dysplasias are composed mainly of epithelial cells, but they can also have slender axes of connective tissue and small capillaries. Dysplastic cells show alterations in polarity, changes in the size and shape of nuclei and some of them show the appearance of signet ring cells. There are also abundant mitotic figures (Fig. 1e). These dysplasias are detected in $44 \%$ of cases. 

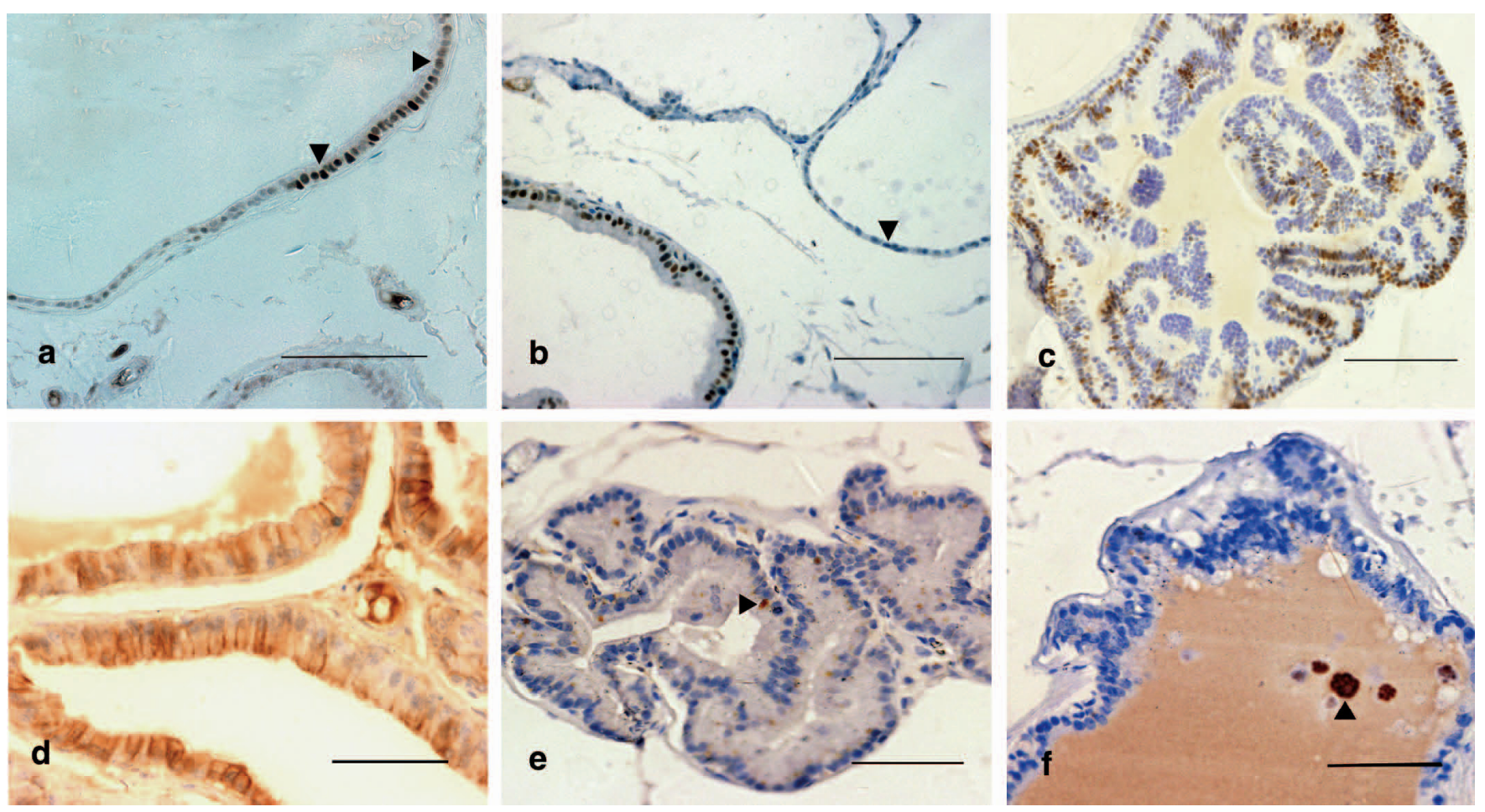

Fig. (2). Immunohistochemical study:

a- Immunoreactive nuclei to PCNA (arrowheads) in the prostatic epithelium of a control rat. The bar represents $100 \mu \mathrm{m}$.

b- No immunoreactivity to PCNA in the atrophic epithelium (arrowhead) of a rat treated with soy. The bar represents $100 \mu \mathrm{m}$.

c- Numerous immunostained nuclei for PCNA in a dysplastic acinus of a soy treated rat. The bar represents $100 \mu \mathrm{m}$.

d- Positive E-cadherin immunostaining between the epithelial cells of a control rat. The bar represents $50 \mu \mathrm{m}$.

e- Positive immunostaining for cleaved caspase 3 (arrowhead) in epithelial cells of a control rat. The bar represents $250 \mu \mathrm{m}$.

f- Cleaved caspase 3 immunostained cells inside a control rat acinus (arrowhead). The bar represents $250 \mu \mathrm{m}$.

Prostatitis was detected in $22 \%$ of controls, characterized by infiltration of leukocytes and macrophages in acinar lumen and in the interstitium (Fig. 1f). Fibrosis was occasionally found in interstitial areas too (Fig. 1g).

The group fed with soy enriched chow, had the epithelium quite similar to controls but showing extensive areas of atrophy (Fig. 1h). This implicates a reduction on the size of cells, showing a remarkable flattening of the epithelium. The periglandular stroma had no modifications comparing to the control group.

Dysplasias with a cribriform structure appear in $23 \%$ of animals (Fig. 1i). Prostatitis was detected in $8 \%$ of the cases and fibrosis in $23 \%$.

In all cases, treated or not, there is remarkable immunoreactivity for PCNA in the nuclei of epithelial cells of prostatic acini (Fig. 2a-c). This expression is in particular much less prominent in the atrophic epithelium in animals treated with soy (Fig. $\mathbf{2 b}$ ).

E-cadherin is expressed in the contact areas between epithelial cells, showing an immunostained band in the apical juncture of epithelial cells. It is abundantly expressed in all animals in the study (Fig. 2d).

The immunoreactivity for cleaved caspase 3 shows a granular expression in the cytoplasm of isolated epithelial cells and is also seen in cells shed from the epithelium to the lumen of the acini (Fig. 2e, f).

\section{Quantitative Results}

The total volume $(\mathrm{Vt})$ of the prostate decreased significantly in soy treated animals (Fig. 3a). However, the ventral prostate volume $(\mathrm{Vv})$ presents no significant differences with controls, although it tends to decrease (Fig. 3b). The volume fraction $\left(\mathrm{V}_{\mathrm{v}}\right.$ ep) and absolute volume (V ep) of epithelium present no significant differences, although they are also lower than in controls (Fig. 3c, d). The volume fraction $\left(\mathrm{V}_{\mathrm{v}}\right.$ Lumen) and absolute volume (V Lumen) of glandular lumen do not present significant differences between controls and animals treated with soy (Fig. 3e, f).

The numerical density (Nv) is significantly higher in soy treated animals than in controls. The absolute number $(\mathrm{Nt})$ of epithelial cells presents no significant differences with controls, although it is higher in animals treated with soy (Fig. 4a, b).

The labeling index of PCNA and cleaved caspase 3 are significantly decreased in soy treated animals. The volume fraction and absolute volume of E-cadherin were also significantly lower in treated rats than in controls (Fig. 5a-d). The qualitative results shown in Figs. (3-5), are summarized in Table 1.

\section{DISCUSSION}

Since there are no significant weight differences between treated and non-treated rats, there is no weight loss attributable to soy. Therefore, prostate damages, must be associated either to treatment or aging. 

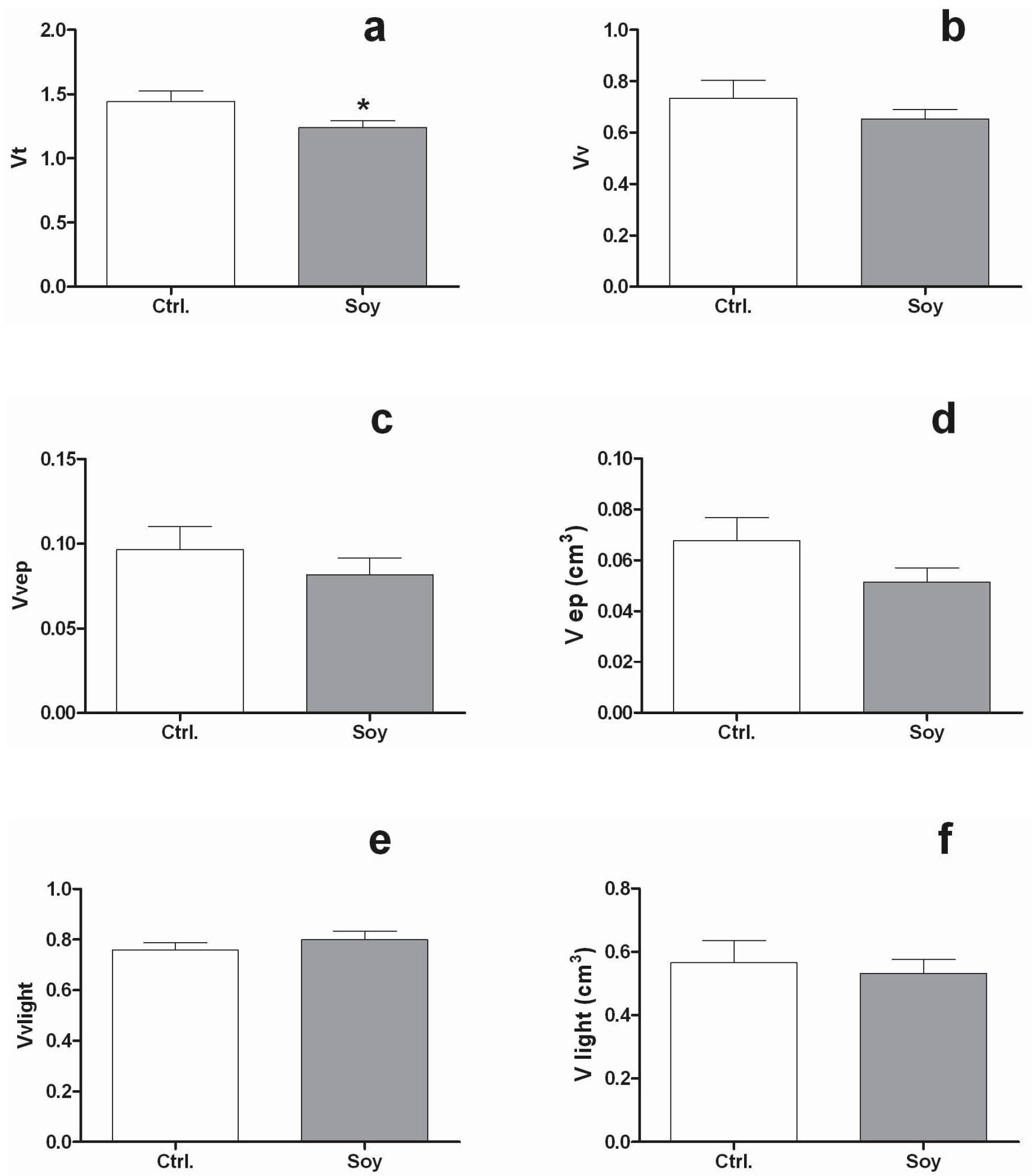

Fig. (3). Quantification of prostate volumes: Results are expressed as mean \pm SD. Asterisks indicate there are significant differences between groups $(\mathrm{p}<0.05)$. a) Bar graph of total prostate volume in controls and in soy treated animals. b) Bar graph of the volume of the ventral prostate in the control group and in the soy treated group. c) Bar graph of the volume fraction of the ventral prostate epithelium in the control group and in soy treated group. d) Bar graph of total volume of the ventral prostate epithelium in the control group and in soy treated group expressed in $\mathrm{cm}^{3}$. e) Bar graph of the volume fraction of gland lumen in the ventral prostate of controls and animals treated with soy. f) Bar graph of total volume of gland lumen in the ventral prostate of controls and animals treated with soy expressed in $\mathrm{cm}^{3}$. 
a

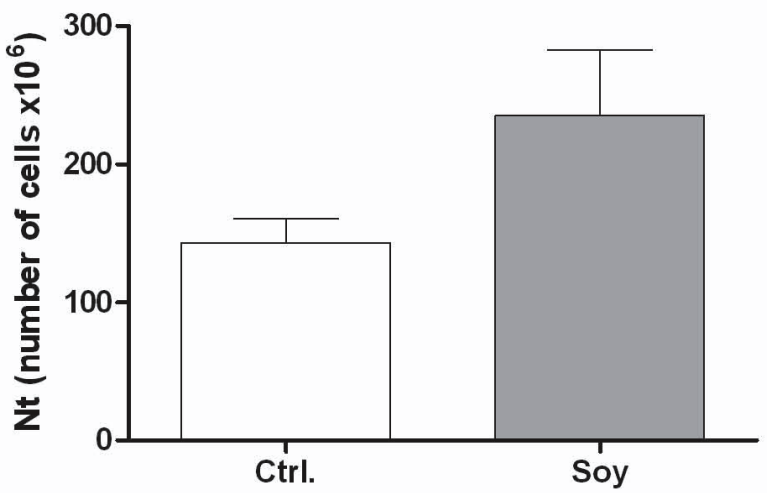

b

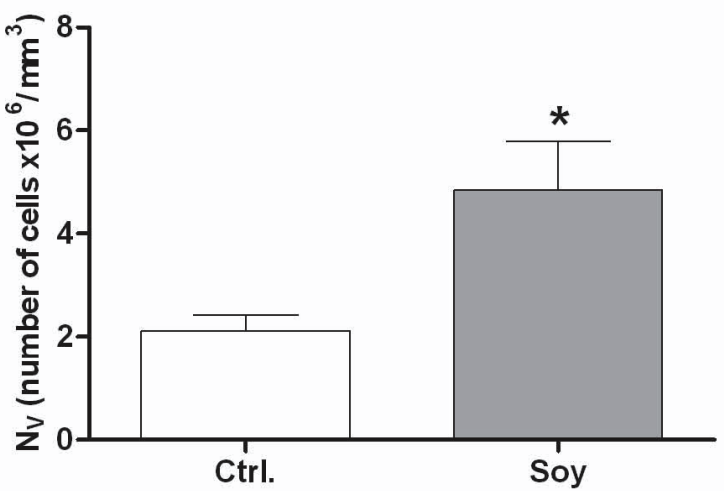

Fig. (4). Quantification of the numerical density and total number of cells in the prostate epithelium; Results are expressed as mean \pm SD. Asterisks indicate significant differences between groups $(\mathrm{p}<0.05)$. a) Bar graph of total number of cells in the ventral prostate epithelium of the control group and the soy treated group. b) Bar graph of the numerical density of cells in the ventral prostate epithelium of the control group and the soy treated group.

a
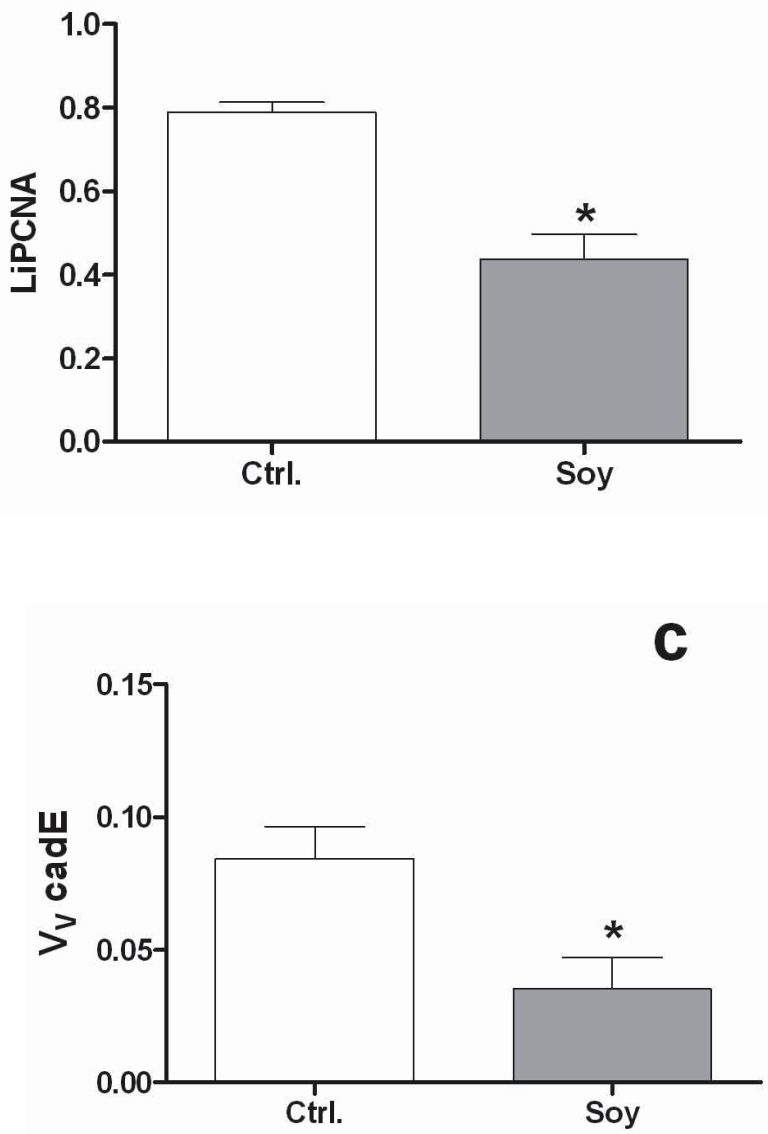
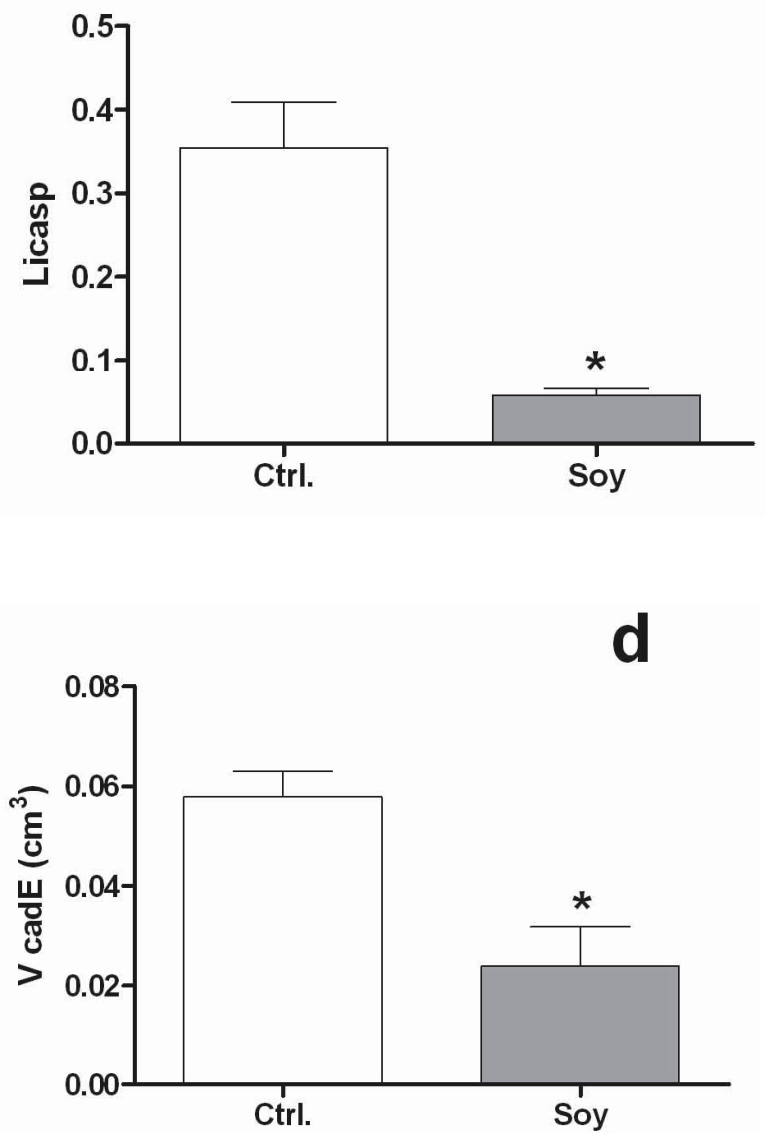

Fig. (5). Quantification of labeling indices and volumes of immunostaining; Results are expressed as mean \pm SD. Asterisks indicate significant differences between groups $(\mathrm{p}<0.05)$. a) Bar graph of PCNA labeling index in the control group and in the treatment group. b) Bar graph of cleaved caspase 3 labeling index in the control group and in the soy treated group. c) Bar graph of the volume fraction of E-cadherin in the control group and in the soy treated group. d) Bar graph of the absolute volume of E cadherin in the control group and in soy treated group. 
Table 1. Summary of results expressed in figures 3-5.

\begin{tabular}{|c|c|}
\hline Quantificated Feature & $\begin{array}{l}\text { Significant Differences Between Groups } \\
\qquad \mathbf{p}<(\mathbf{0 . 0 5})\end{array}$ \\
\hline Volume of the ventral prostate & No \\
\hline Volume fraction of the ventral prostate epithelium & No \\
\hline Volume fraction of gland lumen in the ventral prostate & No \\
\hline Total volume of gland lumen in the ventral prostate & No \\
\hline Total number of cells in the ventral prostate epithelium & No \\
\hline Cleaved caspase 3 labeling index & Yes \\
\hline Volume fraction of E-cadherin & Yes \\
\hline Absolute volume of E cadherin & Yes \\
\hline
\end{tabular}

In the present study some animals in the control group developed dysplastic lesions in the ventral prostate, beginning with a simple thickening of the epithelium and becoming a true epithelial dysplasia. This progression could be associated with aging, since it affected the untreated group. In animals fed with soy-enriched chow, the frequency of dysplasia is lower than in controls. This might be due to the estrogenic activity of soy that may have affected the development of prostate epithelium and then could protect against the development of dysplastic lesions.

Some studies show that prostatitis promotes changes in the epithelium that may evolve to a benign hyperplasia or even cancer [31,32]. Prostatitis found in the control group is also a damage associated with aging [24]. The percentage of prostatitis in the soy treated group was smaller than in the control group, according to several studies [11,33]. Kwon et al. [34] show that subcutaneous administration of isoflavones or orally administrated in pharmacologic doses (50$500 \mathrm{mg} / \mathrm{kg} /$ day), may cause prostatitis but confined to the lateral prostate. In this work we used doses within that range, but we did not study the lateral prostate with the exception of the gland volume, which may change due to prostatitis.

Loeb et al. [32] indicate that the volume of the prostate differs widely between individuals of advanced age. This is because it is common to develop hyperplasia with age, but it is also usual that the aging epithelium suffers an atrophic process as a result of a diminished testicular function. Therefore, we may find aged individuals that have their prostate volume increased and others in which it remains unchanged or even decreased.

In soy-treated animals, the epithelium of the prostate acini shows an atrophic process much more relevant than in controls. Cline et al. [35] described this effect of the soy and associated it to its estrogenic activity. Quantitatively, there is a decrease in the volume of the epithelium but it is not significant. The volume of the gland lumen does not have much variation, neither does the ventral prostate volume. However, there is a significant change in the overall volume of the prostate, so the changes in the gland volume should have occured mainly in the dorsolateral lobes of the prostate.

In this study the ventral lobes were chosen instead of the dorsolateral ones because there are many studies that have not found dysplasias in the dorsolateral lobes and others that show them in the ventral prostate [36-38].

The amount of epithelial cells per unit of epithelial volume was significantly increased in soy-treated rats. This increase in the relative number of cells is due to the atrophy of the epithelium and does not reflect a true increment of the total number of cells, because the absolute size of the epithelium in treated animals is quite similar to that observed in the control group. This insignificant change in the total number of cells could be related to the low expression of cleaved caspase 3 in soy-treated animals. The cleaved caspase 3 is one of the molecules involved in the activation of apoptosis, so in the group treated with soy this process is considerably less active than in controls. A lower rate of cellular death may turn out in a higher number of cells, although they are old aged, which may be associated to the atrophy observed in the epithelium. Having a higher number of cells in the same volume of epithelium, the numerical density is increased.

PCNA expression has been used in numerous studies as a marker of cell proliferation and it is even being considered to improve the accuracy in the diagnosis of prostate cancer [39, 40]. Abundant expression of PCNA was found in all animals in this study except in atrophic areas. 
In soy-treated animals there where many atrophic areas, and it is in this group that we found a lower PCNA labeling index. This suggests that there is less cell proliferation by treating animals with soy, which can also be related to the atrophy observed in the epithelium.

Many works studying the effect of soy and its derivatives against cancer conclude that it is due to its estrogenic effects that the soy modulates the expression of certain genes, mostly related to cell proliferation. Many of these studies, using the PCNA labeling index, found that cell proliferation decreases when treating animals with soy or its derivatives $[41,42]$. This agrees with our results.

There is evidence that the estrogenic effect of soy also affects genes that regulate the expression of E-cadherin [43, 44]. Soy causes atrophy in the epithelium. Therefore there is less contact surface between epithelial cells and the expression of E-cadherin may be reduced. Thus, although soy intake reduces the incidence of dysplastic lesions, it may increase the number of invasive tumors in animals that already have tumors [45].

The following conclusion can be drawn: a) Soy treatment induces atrophy in the epithelium, which is evidenced by an increased cell density without changes in the absolute number of cells. b) Soy intake over a long period may reduce the prostatic cell proliferation as it is shown in the PCNA labeling index. c) The apoptosis is also diminished through caspases way. d) The expression of E-cadherin is reduced probably due to the reduction of the epithelium thickness.

\section{CONFLICT OF INTEREST}

The authors confirm that this article content has no conflict of interest.

\section{ACKNOWLEDGEMENTS}

Declared none.

\section{REFERENCES}

[1] Adlercreutz H. Western diet and Western diseases: some hormonal and biochemical mechanisms and associations. Scand J Clin Lab Invest Suppl 1990; 201: 3-23.

[2] Cook LS, Goldoft M, Schwartz SM, Weiss NS. Incidence of adenocarcinoma of the prostate in Asian immigrants to the United States and their descendants. J Urol 1999; 161 (1): 152-5.

[3] Mäkelä SI, Pylkkänen LH, Santti RSS, Adlercreutz H. Dietary soybean may be antiestrogenic in male mice. J Nutr 1994; 125(3): 437-45.

[4] Zhou JR, Gugger ET, Tanaka T, Guo Y, Blackburn GL, Clinton SK. Soybean phytochemicals inhibit the growth of transplantable human prostate carcinoma and tumor angiogenesis in mice. J Nutr 1999; 129(9): 1628-35.

[5] Weber KS, Setchell KDR, Stocco DM, Lephart ED. Dietary soyphytoestrogens decrease testosterone levels and prostate weight without altering LH, prostate $5 \alpha$-reductase or testicular steroidogenic acute regulatory peptide levels in adult male SpragueDawley rats. J Endocrinol 2001; 170(3): 591-9.

[6] Lee MM, Gomez SL, Chang JS, Wey M, Wang RT, Hsing AW. Soy and isoflavone consumption in relation to prostate cancer risk in China. Cancer Epidemiol 2003; 12(7): 665-8.

[7] Takimoto $\mathrm{CH}$, Glover K, Huang X, et al. Phase I pharmacokinetic and pharmacodynamic analysis of unconjugated soy isoflavones administered to individuals with cancer. Cancer Epidemiol 2003; 12(11 Pt 1): 1213-21.
[8] Hikosaka A, Asamoto M, Hokaiwado N, et al. Inhibitory effects of soy isoflavones on rat prostate carcinogenesis induced by 2 -amino1-methyl-6-phenylimidazo[4,5-b]pyridine (PhIP). Carcinogenesis 2004; 25(3): 381-7.

[9] Ohta T, Nakatsugi S, Watanabe K, et al. Inhibitory effects of Bifidobacterium-fermented soy milk on 2-amino-1-methyl-6phenylimidazo[4,5-b]pyridine-induced rat mammary carcinogenesis, with a partial contribution of its component isoflavones. Carcinogenesis 2000; 21(5): 937-41.

[10] Mäkelä S, Santti R, Salo L, McLachlan JA. Phytoestrogens are partial estrogen agonist in the adult male mouse. Environ Health Perspect 1995; 103(7): 123-7.

[11] Yatkin E, Streng T, Kauppila ML, Bernoulli J, Saarinen N, Santii $\mathrm{R}$. The soy effect in the disease models of non-bacterial prostatitis and obstructive voiding. Exp Biol Med 2007; 232(5): 674-81.

[12] Wang S, DeGroff VL, Clinton SK. Tomato and soy polyphenols reduce insulin-like growth factor-I-stimulated rat prostate cancer cell proliferation and apoptotic resistance in vitro via inhibition of intracellular signaling pathways involving tyrosine kinase. J Nutr 2003; 133(7): 2367-76.

[13] Fotsis T, Pepper M, Adlercreutz H, Hase T, Montesano R, Schweigerer L. Genistein, a dietary ingested isoflavonoid, inhibits cell proliferation and in vitro angiogenesis. J Nutr 1995; 125 (Suppl 3): S790-7.

[14] Wei H, Wei L, Frenkel K, Bowen R, Barnes S. Inhibition of tumor promoter-induced hydrogen peroxide formation in vitro and in vivo by genistein. Nutr Cancer 1993; 20(1): 1-12.

[15] Mahmoud AM, Yang W, Bosland MC. Soy isoflavones and prostate cancer: a review of molecular mechanisms. J Steroid Biochem Mol Biol 2014; 140: 116-32.

[16] Ahmad A, Biersack B, Li Y, et al. Perspectives on the role of isoflavones in prostate cancer. AAPS J 2013; 15(4): 991-1000.

[17] Weinstein MH. Digital image analysis of proliferative index: two distinct populations of high-grade prostatic intraepithelial neoplasia in close proximity to adenocarcinoma of the prostate. Hum Pathol 1998; 29(6): 620-6.

[18] Xie W, Wong YC, Tsao SW. Correlation of increased apoptosis and proliferation with development of prostatic intraepithelial neoplasia (PIN) in ventral prostate of the Noble rat. Prostate 2000; 44(1): 31-9.

[19] Arriazu R, Pozuelo JM, Martín R, Rodríguez R, Santamaría L. Quantitative and immunohistochemical evaluation of PCNA, androgen receptors, apoptosis and Glutathione-S-Transferase P1 on preneoplastic changes induced by cadmium and zinc chloride in the rat ventral prostate. Prostate 2005; 63(4): 347-57.

[20] Woo M, Hakem R, Soengas MS, et al. Essential contribution of caspase $3 / \mathrm{CPP} 32$ to apoptosis and its associated nuclear changes. Genes Dev 1998; 12(6): 806-19.

[21] Winter RN, Kramer A, Borkowsky A, Kyprianou N. Loss of caspase-1 and caspase-3 protein expression in human prostate cancer. Cancer Res 2001; 61(3): 1227-32.

[22] Mahnken A, Kausch I, Feller AC, Krüger S. E-cadherin immunoreactivity correlates with recurrence and progression of minimally invasive transitional cell carcinomas of the urinary bladder. Oncol Rep 2005; 14(4): 1065-70.

[23] Moyano Calvo JL, Blanco Palenciano E, Beato Moreno A, et al. [Prognostic value of E-cadherina, beta catenin, Ki-67 antigen and p53 protein in the superficial bladder tumors]. Actas Urol Esp 2006; 30(9): 871-8.

[24] Arriazu R. Estudio inmunohistoquímico y cuantitativo de la lesión displásica inducida por cloruro de cadmio en la próstata ventral de la rata. Tesis Doctoral: Universidad San Pablo CEU 2003.

[25] Hamana T, Kawai K, Serizawa A, Tsutsumi Y, Watanabe K. Immunohistochemical demonstration of $\mathrm{p} 53$ protein in colorectal adenomas and adenocarcinomas. Reliable application of the heatinduced antigen retrieval method to formalin-fixed, paraffinembedded material. Pathol Int 1994; 44(10-11): 765-70.

[26] Ramirez R, Martin R, Martin JJ, Ramirez JR, Paniagua R, Santamaria L. Changes in the number, proliferation rates, and bcl-2 protein immunoexpression of epithelial and periductal cells from rat epididymis during postnatal development. J Androl 1999; 20(6): 702-12.

[27] Gundersen HJ, Osterby R. Optimizing sampling efficiency of stereological studies in biology: or 'do more less well!'. J Microsc 1981; 121(Pt 1): 65-73. 
[28] Howard CV, Reed MG. Unbiased Stereology: three-dimensional measurement in microscopy. $2^{\text {nd }}$ ed. Oxford: Bios Scientific Publishers 2005

[29] Pozuelo JM, Rodríguez R, Arriazu R, Ingelmo I, Martín R, Santamaría L. Changes in the number and volume of NPY and VIP neurons from periprostatic accessory vegetative ganglia in pre- and peripuberal rats. A stereological study. Tissue Cell 2010; 42(1): 18.

[30] Sterio DC. The unbiased estimation of number and sizes of arbitrary particles using the disector. J Microsc 1984; 134 (Pt 2): 12736.

[31] Elkahwaji JE, Hauke RJ, Brawner CM. Chronic bacterial inflammation induces prostatic intraepithelial neoplasia in mouse prostate. Br J Cancer 2009; 101(10): 1740-8.

[32] Loeb S, Kettermann A, Carter HB, Ferrucci L, Metter EJ, Walsh PC. Prostate volume changes over time: results from the Baltimore Longitudinal Study of Aging. J Urol 2009; 182(4): 1458-62.

[33] Sharma OP, Adlercreutz H, Strandberg JD, Zirkin BR, Coffey DS, Ewing LL. Soy of dietary source plays a preventive role against the pathogenesis of prostatitis in rats. J Steroid Biochem Mol Biol 1992; 43(6): 557-64.

[34] Kwon SM, Kim SI, Chung DC, et al. Development of rat prostatitis model by oral administration of isoflavone and its characteristics. Yonsei Med 2001; 42(4): 395-404.

[35] Cline JM, Franke AA, Register TC, Golden DL, Adams MR. Effects of dietary isoflavone aglycones on the reproductive tract of male and female mice. Toxicol Pathol 2004; 32(1): 91-9.

[36] Waalkes MP, Rehm S. Cadmium and prostate cancer. J Toxicol Environ Health 1994; 43(3): 251-69.

[37] Martin JJ, Martin R, Codesal J, Fraile B, Paniagua R, Santamaria L. Cadmium chloride-induced dysplastic changes in the ventral rat prostate: an immunohistochemical and quantitative study. Prostate 2001; 46(1): 11-20.

[38] Waalkes MP. Cadmium carcinogenesis in review. J Inorg Biochem 2000; 79(1-4): 241-4.

[39] Lai JS, Xia Q, Zhang XB, Zhao GP, Xu SL, Zheng DS. Expression and significance of PCNA and p27 in benign prostate hypertrophy and prostate carcinoma. Zhonghua Zhong Liu Za Zhi 2004; 26(8): 476-8.

[40] Zhong W, Peng J, He H, et al. Ki-67 and PCNA expression in prostate cancer and benign prostatic hyperplasia. Clin Invest Med 2008; 31(1): E8-15.

[41] Kim HA, Jeong KS, Kim YK. Soy extract is more potent than genistein on tumor growth inhibition. Anticancer Res 2008; 28(5A): 2837-41.

[42] Yu JY, Lee JJ, Lim Y, et al. Genistein inhibits rat aortic smooth muscle cell proliferation through the induction of $\mathrm{p} 27 \mathrm{kip} 1$. J Pharmacol Sci 2008; 107(1): 90-8.

[43] Su Y, Simmen FA, Xiao R, Simmen RC. Expression profiling of rat mammary epithelial cells reveals candidate signaling pathways in dietary protection from mammary tumors. Physiol Genom 2007; 30(1): 8-16.

[44] Su Y, Simmen RC. Soy isoflavone genistein upregulates epithelial adhesion molecule E-cadherin expression and attenuates betacatenin signaling in mammary epithelial cells. Carcinogenesis 2009; 30(2): 331-9.

[45] Dave B, Wynne R, Su Y, Korourian S, Chang JC, Simmen RC. Enhanced mammary progesterone receptor-A isoform activity in the promotion of mammary tumor progression by dietary soy in rats. Nutr Cancer 2010; 62(6): 774-82

Received: January 28, 2014

Revised: May 20,2014

Accepted: May 22, 2014

(C) Oltra et al.; Licensee Bentham Open.

This is an open access article licensed under the terms of the Creative Commons Attribution Non-Commercial License (http://creativecommons.org/licenses/by-nc/3.0/) which permits unrestricted, non-commercial use, distribution and reproduction in any medium, provided the work is properly cited. 